\title{
Kashmiri Language
}

National Cancer Institute

\section{Source}

National Cancer Institute. Kashmiri Language. NCI Thesaurus. Code C153971.

A language from the Dardic subgroup of Indo-Aryan languages spoken primarily in the Kashmir Valley and Chenab Valley of the Jammu and Kashmir state in India. 